\title{
An Empirical Study on Chinese and American College Students' Moral Value Recognition
}

\author{
Zhu Hailong \\ (Guangdong University of Foreign Studies, longhua_88623@126.com)
}

\section{Introduction}

College students are the heirs apparent to the will of the state and the traditional culture. Their identification of moral values not only affects strategic considerations of cultural safety, but also directly affects moral education. Given that China has a deep traditional moral culture and the United States has advanced cultural productivity, this study evaluated moral values among college students in both countries. Specifically, it distributed a survey on moral value recognition to 900 undergraduate students at 12 universities in China and the United States. The study's purpose is to discuss the current role of college students' moral values in Chinese and American identities, verify the possibility of generalizing traditional Chinese moral values, and provide a theoretical basis and data support for delivering moral education to college students.

This study tests whether American college students are willing to accept the moral values also contained in traditional Chinese culture, using experimental measurement and theoretical analysis. This analysis interprets the similarities and differences between Chinese and American college students' cognition of moral values, and explores the possibility of traditional Chinese moral values' generalizability.

\section{Methods}

Participants

This study selected Chinese ( $\mathrm{n}=743,354$ males and 389 females) and American ( $\mathrm{n}=157,80$ males and 77 females) undergraduate students as samples. The effective Chinese sample rate is $92.9 \%$, and the Chinese participants come from Beijing Normal University, Xinjiang Financial University, Changsha Normal University, Three Gor- 
ges University, Southwest University, Sun Yat-sen University, South China University of Science and Engineering, and Guangdong University of Foreign Studies. The effective American sample rate is $87.2 \%$, and the American participants come from Illinois State University, Fordham University, Boston University, and The Ohio State University.

\section{Measures}

The study uses a self-designed questionnaire called the Survey of College Students' Chinese Moral Value Recognition. Because moral values consist of multidimensional psychological structures, a pre-test and factor analysis included interviews with moral education experts, teachers, and college students. Based on the pre-test results, the tested moral values were divided into six dimensions: honesty, civility \& self-discipline, benevolence, unity \& helping others, esteem, and filial piety. The questionnaire conforms to the core values of traditional Chinese moral culture and contains 31 items. Its Cronbach's alpha coefficient is 0.899 and split-half reliability is 0.867 . The internal factors of the questionnaire are distinct and it has excellent structural validity. A 5-point Likert scoring method was used and tested by taking a unit. The SPSS 16.0 software was used to conduct statistical processing.

\section{Results. Moral Value Comparison between Chinese and American College Students}

Table 1 presents descriptive statistics on Chinese college students' recognition of the tested moral value dimensions. The scores followed this ranking, from high to low: honesty, civility \& self-discipline, filial piety, unity \& helping others, benevolence, and esteem.

\begin{tabular}{|lccccc|}
\hline & N & Minimum & Maximum & Mean & $\begin{array}{l}\text { Std. } \\
\text { Deviation }\end{array}$ \\
\cline { 2 - 3 } & 743 & 2.71 & 4.90 & 4.055 & 0.408 \\
Honesty & 743 & 2.40 & 5.00 & 4.266 & 0.455 \\
$\begin{array}{l}\text { Civility \& Self- } \\
\text { Discipline }\end{array}$ & 743 & 2.00 & 5.00 & 4.192 & 0.538 \\
Benevolence & 743 & 2.13 & 5.00 & 3.917 & 0.601 \\
Unity \& & 743 & 2.33 & 5.00 & 4.044 & 0.514 \\
Helping & & & & & \\
Others & 743 & 1.60 & 5.00 & 4.131 & 0.516 \\
Filial Piety & 743 & 2.50 & 5.00 & 3.884 & 0.489 \\
Esteem & 743 & & & & \\
Valid & & & & & \\
\hline
\end{tabular}


Table 2 shows descriptive statistics from the American students, who followed this ranking: honesty, civility \& self-discipline, filial piety, and benevolence.

\begin{tabular}{cccccc}
\hline & N & Minimum & Maximum & Mean & $\begin{array}{c}\text { Std. } \\
\text { Deviation }\end{array}$ \\
\hline Total & 157 & 2.91 & 4.74 & 4.037 & 0.382 \\
\hline Honesty & 157 & 3.00 & 5.00 & 4.245 & 0.434 \\
$\begin{array}{c}\text { Civility \& Self- } \\
\text { Discipline }\end{array}$ & 157 & 2.33 & 5.00 & 4.089 & 0.604 \\
\hline Benevolence & 157 & 2.13 & 5.00 & 4.008 & 0.537 \\
Unity \& & 157 & 2.17 & 5.00 & 3.910 & 0.615 \\
Helping & & & & & \\
\hline Others & 157 & 2.80 & 5.00 & 4.077 & 0.508 \\
\hline Filial Piety & 157 & 2.75 & 5.00 & 3.940 & 0.475 \\
\hline Esteem & 157 & & & & \\
\hline Valid N & & & &
\end{tabular}

Table 2: American College Students' Moral Values Recognition

These statistics show some differences in moral priorities between the two groups, as summarized in Tables 3 and 4.

\begin{tabular}{ccccccc}
\hline $\begin{array}{c}\text { Moral value } \\
\text { dimension }\end{array}$ & Honesty & $\begin{array}{c}\text { Civility } \\
\text { and Self- } \\
\text { Discipline }\end{array}$ & $\begin{array}{c}\text { Filial } \\
\text { Piety }\end{array}$ & $\begin{array}{c}\text { Unity and } \\
\text { Helping } \\
\text { Others }\end{array}$ & Bnevolence & Esteem \\
\hline $\begin{array}{c}\text { Chinese } \\
\text { College } \\
\text { Students }\end{array}$ & 1 & 2 & 3 & 4 & 5 & 6 \\
$\begin{array}{c}\text { American } \\
\text { College } \\
\text { Students }\end{array}$ & 1 & 2 & 3 & 6 & 4 & 5 \\
\hline
\end{tabular}

Table 3: Overall Ranking of Chinese and American College Students' Moral Values Recognition 


\begin{tabular}{cccccc}
\hline & Country & $\mathrm{N}$ & Mean & $\begin{array}{c}\text { Std. } \\
\text { Deviation }\end{array}$ & $\begin{array}{c}\text { Std. Error } \\
\text { Mean }\end{array}$ \\
\hline Total & U.S. & 157 & 4.038 & 0.382 & 0.031 \\
Honesty & China & 743 & 4.055 & 0.408 & 0.015 \\
& U.S. & 157 & 4.246 & 0.435 & 0.035 \\
Civility & China & 743 & 4.267 & 0.456 & 0.017 \\
\& Self- & U.S. & 157 & 4.090 & 0.604 & 0.048 \\
Discipline & China & 743 & 4.193 & 0.538 & 0.020 \\
& U.S. & 157 & 4.011 & 0.538 & 0.043 \\
Unity \& & China & 743 & 3.917 & 0.602 & 0.022 \\
Others & U.S. & 157 & 3.910 & 0.616 & 0.019 \\
Filial Piety & China & 743 & 4.044 & 0.514 & 0.049 \\
& U.S. & 157 & 4.078 & 0.508 & 0.041 \\
Esteem & China & 743 & 4.131 & 0.517 & 0.019 \\
& U.S. & 157 & 3.940 & 0.475 & 0.038 \\
& China & 743 & 3.884 & 0.489 & 0.018 \\
\hline
\end{tabular}

Table 4: Differences in Chinese and American College Students' Moral Values Recognition

As shown in Table 4, the average scores of Chinese college students are higher than those of American students in honesty, civility \& self-discipline, unity \& helping others, and filial piety, but lower than American students in benevolence and esteem. An independent samples T-test showed that there are significant differences between China and USA in the dimensions of civility and self-discipline and unity and helping others, as shown in Table 5:

\begin{tabular}{lll}
\hline & $\mathrm{T}$ & Sig (2-tailed) \\
\hline Total & -0.517 & 0.606 \\
Honesty & -0.542 & 0.588 \\
$\begin{array}{l}\text { Civility \& Self- } \\
\text { Discipline }\end{array}$ & -1.973 & $0.050^{*}$ \\
Benevolence & 1.936 & 0.054 \\
$\begin{array}{l}\text { Unity \& Helping } \\
\text { Others }\end{array}$ & -2.564 & $0.011^{*}$ \\
Filial Piety & -1.199 & 0.232 \\
Esteem & 1.317 & 0.189 \\
\hline
\end{tabular}

Table 5: Independent Samples Test

$* \mathrm{P}<0.05$ significant; $* * \mathrm{P}<0.01$ significant; *** $\mathrm{P}<0.001$ significant 
To verify the accuracy of the existing conclusion in greater depth, in accordance with the idea of same-sample measurement, we selected data from 157 of the Chinese students at random, and compared it to data from the 157 American students. Further statistical analysis showed although the specific numbers changed, the Chinese college students had higher scores than the American students overall, but they scored lower than the American students in benevolence and esteem. Thus, our earlier finding that Chinese students scored higher in the other four dimensions did not change substantially.

\section{Data Analysis}

From the statistical data, we find no significant cognitive differences between Chinese and American college students in the four moral value dimensions of honesty, benevolence, filial piety, and esteem. This verifies the generality of these traditional moral values originating in Chinese culture. However, at the same time there were significant differences in civility \& self-discipline and unity \& helping others.

\section{Discussion. Similarities Between Chinese and American Students' Moral Values}

The independent samples T-test showed a $\mathrm{P}$ value greater than 0.05 for both groups' views of honesty, benevolence, filial piety, and esteem, indicating that Chinese and American college students have no significant differences in these four dimensions of moral values. This similarity proves the generality of these traditional Chinese moral values. In fact, in 1989, a number of Western scholars (including 75 Nobel laureates) solemnly declared, "If humans want to survive in the 21st century and avoid confusion, it is necessary to look back 2500 years to the moral wisdom of Confucius" (Wang Dianqing 1999). From the results of this experiment, it is not difficult to find that the impact of moral values originating from traditional culture is extensive and far-reaching for both Chinese and American college students. In addition, the moral values of traditional Chinese culture not only have strong Chinese characteristics but also intersect with traditional American moral values. It is the common accomplishment of human moral values to meet the basic needs of individual moral development. Even though knowledge, benevolence, and courage belong to the Chinese "three kinds of character," while wisdom, justice, boldness, and temperance are attached to the ancient Greek "four main virtues," they undoubtedly all reflect the intersection of Chinese and western moral values. This similarity is a powerful counterblow to the alienation caused by value relativism within multicultural perspectives.

Chinese and American college students' recognition of traditional moral values benefits from the process of virtue ethics culture regression and the two countries' strengthening of moral education. China began to break up the inefficiency of college students' moral education with the idea of educating people with culture. This not only shaped the cultural atmosphere of upholding ethics, esteeming virtue, and doing good things, but also took traditional culture as the background for core socialist values, 
cultivating college students' cultural awareness, cultural self-confidence, and cultural self-improvement. Lots of Confucian groups have likewise appeared in American giving American college students closer contact with the enduring charm of Chinese traditional moral culture. As for the US, several rounds of innovation since the 1920s have finally established traditional moral values education, giving American college students significant common ground with Chinese traditional moral values. It is easy for both groups to agree on certain moral values. At the same time, the unique function of Chinese cultural and moral wisdom in solving ecological imbalance, moral decadence, and interpersonal conflict enhances the confidence of Chinese college students in Chinese traditional culture. Thus, it is possible for the two countries' college students to develop value recognition.

Both groups of students recognized honesty, civility \& self-discipline, and filial piety in the same order of priority, demonstrating that both cultures share these aspirations. It also proved that Chinese traditional culture has generality in dissolving cultural conflicts. Regarding the specific rankings, honesty is ranked highest due to the rapid development of economic globalization not bringing social and moral growth. Instead, the negative effects of value relativism, individualism, and materialism in society have become more and more serious. Selfishness, cheating, and treachery are common, which is sure to produce a lasting shock to college students. Thus, we can understand college students' desires for an authentic and honest social environment.

Civility and self-discipline is in second place, not only indicating an ardent yearning for civilization, but also reflecting their own educational attainments. In recent years, college students' immoral behaviors have gone beyond disrespect, skipping classes, and cheating: they turn to immoral values, behaving outrageously and even criminally. So, what is the standard of right or wrong? Where is the moral bottom line? (Spring, 1994). These problems which should not be problems are more prominent due to the force of value relativism. The need for civility is not only attracting social attention, but also leads to college students' self-examination. The ideas of putting one's mind in a proper and well-ordered condition, getting true ideas, acquiring knowledge, and studying systematically promote ethical behavior through the moral cultivation of see no evil, hear no evil, and speak no evil. This educational philosophy has a profound effect on students who suffered from value relativism.

Filial piety, the core of Chinese traditional morality is in third place. Chinese and American college students identified it as an important moral value, jointly proving that filial piety plays an irreplaceable role in maintaining human relationships and the process of showing affection. Although China and the United States have different political systems, living customs, cultural traditions, and expressions of filial piety, the Protestant ethic's understanding of the value of filial piety produces the biggest intersection with the concept of filial piety in Confucian moral philosophy, leading to this consensus. 


\section{Differences Between Chinese and American Students' Moral Values}

As shown in Table 5, the P values for the dimensions of civility \& self-discipline and unity \& helping others are 0.050 and 0.011 , respectively, indicating significant differences $(\mathrm{P}>0.05)$ between the groups. Table 4 shows that the scores of the Chinese college students in these dimensions are 4.193 and 4.044, compared to 4.090 and 3.910 for the American college students, proving that Chinese student evaluate these values more highly than Americans. The source of this difference can be traced to each country's traditional culture and direction of moral education. In China, the traditional culture extends back five thousand years, and although it has fused with overseas cultures several times, it still retains the mainstream culture of Confucian virtue ethics. These ethics not only include moral requirements with the core of benevolence and etiquette, but also promote moral restraint for individual and social collectivity, a civil personality, and the idea that collective interests exceed personal interests. Such standards seek to unify families, govern countries, and ultimately match inner peace with world peace (Zhao Xudong 2003).

Moreover, the impact of Chinese traditional culture has long been infiltrated by outside behavioral constraints to the spiritual world, which benefited the construction of college students' moral values and promoted the formation of value recognition, civility \& self-discipline, and unity \& helping others through the subtle influence of culture. It is the foothold to deal with value relativism, individualism, materialism, and nihilism within a multicultural background. The positive effects of traditional culture can't be ignored. Starting in the 1980s, China began to pay more attention to the importance of traditional culture's moral influence on college students. In this century, unprecedented attention has been attached to the contemporary meaning of traditional culture, as reflected in the content of moral education and social practice of college students. This may be the reason why Chinese college students got higher scores in the value dimensions of civility \& selfdiscipline and unity \& helping others.

Compared with China, the United States is a very young country established on the basis of immigrants' multiculturalism. Democracy and freedom are the foundation of civic value, individualism is the long-standing cultural tradition, and moral values are considered as personal affairs in a 'private space' that should not be taught in school by force. Over time, the result has been a lack of preparation for dazzling cultural trends and fuzzy value judgments among American college students. What is the scale of civilization? What criteria should be followed? What is the ultimate goal of unity? Thus, misconduct would follow without a doubt. At the same time, the direction of American culture and moral education is erratic, directly affecting the construction of college students' moral values.

Because United States universities do not offer specialized, systematic, and explicit moral education, hidden moral education mainly relies on humanities and social work 
courses. The direction of culture and moral education is fluctuating. From the character education which advocated traditional moral values before the 1920 s to the progressive education in the 1920s and 30s, to value clarification education in the 1950s and 60s, to cognitive morality education in the 1970s and 80s, America finally returned to character education. For nearly a hundred years, moral education was wondering "what kind of moral value should be taught" and "how to get moral value" (Holl, 2003). As a consequence, they blurred the standard of judgment for moral values, lost to the invisible temptation of relativism. The question of why to hold certain moral values affected American college students' scores on these two value dimensions.

\section{Improving Students' Awareness of Moral Values}

Chinese college students' score for esteem was 3.884, their lowest of the six dimensions of moral value, while American college students scored lowest on unity and helping others (3.910). This proves that they all have deficiencies in their ethical levels. Esteem is a necessary virtue which should be insisted on during interpersonal communication. Unfortunately, judging from the misconduct among college students in recent years, many lack esteem consciousness. Since most Chinese undergraduates were born after the 1990s, they are often at the core of three generations living under one roof. Being spoiled caused the problems of self-centeredness, selfishness, poor ability to adapt, low levels of patience, and a fragile sense of cooperation that should be improved immediately. They are accustomed to a self-centered way of thinking: many students lack respect for fellow students and teachers, damaging communications and interpersonal relationships.

This bad result has affected college life, which should be happy. More seriously, the tragedies due to a lack of basic respect for life have an upward tendency, distorting the personality and mental health status of college students. The actions of Liu Haiyang, a college student at Tsinghua University who poured acid on several bears at a zoo, the Ma Jiajue homicide case at Yunnan University, Yao Jiaxing's intentional killing at Xian Conservatory of Music, and the poisoning case of a Fudan University postgraduate, without exception, exposed college students to disregard for other people's lives, a trend also evident in the increased campus suicide rates. These tragedies not only ruin young lives but also their families' happiness. Chinese moral education is severely lacking in the cultivation of the consciousness of respect. Now, we should enrich the content of college students' moral education. Beginning with respect for others' personality, then developing a respect for others' habits and cultural customs will achieve deeper esteem education. The goal is to make equal moral consciousness the spiritual core of Chinese college students.

For American college students, "unity and helping others" is their moral weakness. Since this dimension manifests as collective spirit more often, American college students who 
are used to individualism and the pursuit of freedom feel uncomfortable with it to a certain extent. In recent years, the news that American college students avoid military service, keep away from NGO, hate governmental organizations, and frequently destroy public property prove their lack of unity consciousness. The lack of collectivist value education in American colleges is another cause of this behavior. The content of Dewey's progressive education theory included many traditional moral core values of the United States, and some of them have a close association with unity and helping others. The ecological association tradition is another active influence, so there are no serious flaws on college students' sense of unity. Various moral education innovations focused on some aspect of moral education methods, but ignored the leading role of core moral values to college students. Thus, when American society entered the fast lane of globalization, relativism gave college students who wanted to abandon the collective spirit a plausible moral reason. Fierce competition in society makes them give up unity and collective interests to achieve their goals. On the other hand, college students who are willing to stay together for collective interests become more and more scarce. It is not difficult to see that the collectivist education for American college students needs to be strengthened by the federal government, and college students also should cultivate the self-awakening of unity and helping others.

\section{References}

Holl R. T. 2003. Theory and Practice of Moral Education. Trans. Lu Youquan. Hangzhou: Zhejiang Education.

Spring J. 1994. The American School 1642-1993. New York: McGraw-Hill Companies.

Wang D. 1999. Oriental Moral Research (3rd Series). Beijing: China Industry and Commerce Publishing House.

Zhao X. 2003. Reflection on the Construction of Local Culture. Beijing: Peking University Press.

\section{Acknowledgements}

This article was funded by The China national educational science' Thirteenth 5 Years' management 2018 project "Great civilian and values recognition in new era", No.

BEA180114. 


\author{
Zhu Hailong \\ (Guangdong) \\ An Empirical Study on Chinese and American College Students' \\ Moral Value Recognition
}

\begin{abstract}
This study used a self-designed questionnaire to empirically evaluate Chinese and American undergraduate students' recognition of moral values in six dimensions: honesty, civility \& self-discipline, benevolence, unity \& helping others, esteem, and filial piety. In total, 743 valid samples from 8 Chinese universities and 157 valid samples from 4 American universities were collected for an experimental comparison. Measurement results showed that the differences between Chinese and American college students were not significant in the dimensions of honesty, benevolence, esteem, and filial piety. These values, which originated in traditional Chinese culture, had the same priorities in both groups, confirming a certain degree of universality. However, significant intergroup differences existed in the civility and self-discipline dimension and the unity and helping others dimension. These results highlight the importance of enhancing Chinese college students' moral consciousness, especially with esteem, and of enhancing American students' consciousness of unity and helping others.
\end{abstract}

Keywords: Empirical study; China; American; college students; moral; values; recognition.

Ethics in Progress (ISSN 2084-9257). Vol. 9 (2018). No. 1, Art. \#6, pp. 118-127.

Creative Commons BY-SA 3.0

Doi: 10.14746/eip.2018.1.6 